\title{
Sovereign Credit Risk Assessment with Multiple Criteria Using an Outranking Method
}

\author{
Diogo F. de Lima Silva, ${ }^{1}$ Julio Cezar Soares Silva, ${ }^{1}$ Lucimário G. O. Silva, ${ }^{1}$ \\ Luciano Ferreira, ${ }^{2}$ and Adiel T. de Almeida-Filho $\mathbb{(}^{1}$ \\ ${ }^{1}$ Management Engineering Department, Universidade Federal de Pernambuco, Caixa Postal 7471, 50.630-970 Recife, Brazil \\ ${ }^{2}$ Management School, Universidade Federal do Rio Grande do Sul, Porto Alegre, RS, Brazil \\ Correspondence should be addressed to Adiel T. de Almeida-Filho; ataf@greefo.org.br
}

Received 27 May 2018; Revised 20 July 2018; Accepted 13 August 2018; Published 23 September 2018

Academic Editor: Alessandro Naddeo

Copyright (C) 2018 Diogo F. de Lima Silva et al. This is an open access article distributed under the Creative Commons Attribution License, which permits unrestricted use, distribution, and reproduction in any medium, provided the original work is properly cited.

In view of the records of failures in rating agencies' assessments for sorting countries' quality of credit in degrees of default risk, this paper proposes a multicriteria sorting model using reference alternatives so as to allocate sovereign credit securities into three categories of risk. From a numerical application, what was observed from the results was a strong adherence of the model in relation to those of the agencies: Standard \& Poor's and Moody's. Since the procedure used by the agencies is extremely subjective and often questioned, the contribution of this paper is to put forward the use of an objective and transparent methodology to sort these securities. Given the agencies' conditions for undertaking the assessment, a complete similarity between the results obtained and the assignments of the agencies was not expected. Therefore, this difference arises from subjective factors that the agencies consider but the proposed model does not. Such subjective and questionable aspects have been partly responsible for the credibility of these credit agencies being diminished, especially after the 2007-2008 crisis.

\section{Introduction}

One of the most sought-after types of international investment is sovereign bonds. The risk associated with this type of investment is related to the possibility of a government not paying the agreed yields to the creditor, the analysis of the credit/default risk being important for decision making in finance and banking [1]. In this regard, a number of international agencies, of which Moody's, Standard \& Poor's, and Fitch are the best known, generate reports sorting country bonds at certain levels of risk, expressed as ratings. Canuto et al. [2] define sovereign risk as the credit risk associated with operations involving the credit of sovereign states and explain that the risk agencies' ratings are serious, public domain indicators that contribute to reducing investor uncertainty related to the risks that involve government securities.

The ratings of the agencies that sort risk are viewed by financial agents as efficient for risk management, although they represent a very costly procedure [3]. However, recent events have tarnished the image of these agencies. For many authors, errors in the way that the agencies assess risk were among the reasons for the crisis that began at the end of the last decade [4-8]. For Salvador et al. [4] the subprime crisis began in 2007 with steady declines in sovereign bonds and structured products which brought to the forefront a debate about the quality and the true role of the agencies that rate risk. Among the reasons why the ability of risk agencies is being questioned is the low transparency in how the ratings are attributed [7]. Besides the subprime crisis, the European sovereign debt crisis also had a strong effect on the global market [9-11].

Thus, it is seen that using a structured and transparent model to serve as an indicator for rating sovereign bonds is interesting. This is because this study has analyzed the criticisms made of the current systems used by the major rating agencies and found these to be justifiable. Therefore, the model now put forward includes ways of meeting these criticisms. However, as our model must undergo further rigorous testing in the real world, the intention of this study is not to replace or introduce immediate improvements to 
the methods used by the agencies. On the other hand, the proposed model can be used as an additional tool for assessing and supporting the way that decision making is currently undertaken. If this shows that the proposed model is consistently more accurate, then decision makers (DMs) should consider whether they should adapt their methods or implement the model proposed, albeit in a modified form, if rigorous real world testing indicates this is necessary.

In order to determine a country's ratings, risk agencies need to take a number of different criteria into account. According to Standard \& Poor's [12], five key areas are evaluated in the context of sovereign ratings, namely, institutional assessment, economic assessment, external assessment, fiscal assessment, and monetary assessment. Hoti and Mcaleer [13] explain that country-specific factors can be requested and used to determine risk, besides which financial, political, and economic risks of countries affect each other. In addition, the problems that different countries face may have different origins [14]. Thus, sorting countries at certain levels of risk can be dealt with as a multicriteria decision problem.

A multicriteria decision problem can be classified according to the following problematics: the problem of choice, the problem of sorting, the problem of ordering or the problem of description [15], and the problem of compiling a portfolio. According to Roy [15], the sorting problematic sets out to allocate actions (alternatives) into categories, which are determined a priori following norms that are applicable to the set of actions. This is such a relevant problem formulation that until now there are several recent developments in multiple criteria sorting approaches that can be found in the literature [16-19], emphasizing the relevance of this problematic in different contexts.

This research study fits into the sorting problematic, as it aims to apply a multicriteria sorting model to allocate sovereign bonds into three categories of risk. To do so, a model that infers parameters is used by disaggregating preferences for a sorting method, proposed in [20]. Preference disaggregation consists of an indirect way of eliciting the decision maker's preferences, which arise out of preference examples [21]. In addition, a comparison is made between the results of the proposed model and the allocations of two risk rating agencies, Standard \& Poor's and Moody's, for the year 2014. Using the method proposed by Doumpos and Zopounidis [20], the alternatives are sorted based on peer-topeer comparisons with a set of nine preestablished reference alternatives.

Therefore, the contributions of this paper are twofold. First, it models the sovereign credit risk problem with the use of real objective financial indicators. Investors can use the model to calibrate their decisions and protect them from the subjectivity incorporated by the mostly used rating systems. Second, the paper contributes to the state of the art involving applications of sorting methodologies in finance by applying a literature outranking method based on PROMETHEE with the use of linear programming for parameter inference.

The rest of this paper is organized as follows: Section 2 gives a brief review of sorting multicriteria approaches. Section 3 presents and discusses the materials and methods used while Section 4 presents an MCDM/A model for assessing the risks involved in sovereign credit. The results from applying the model are discussed in Section 5. Finally, some conclusions are drawn in Section 6 which also makes suggestions for future lines of research and summarizes the main contributions of this paper.

\section{MCDM/A for Credit Risk Rating}

The use of Multiple Criteria Decision Making/Aiding (MCDM/A) approaches is necessary to deal with complex decision problems, when several and possibly conflicting objectives are considered [22]. Doumpos and Zopounidis [23] commented about four MCDM/A approaches: Multiobjective Optimization, Multiattribute Value/Utility Theory, Outranking Relations, and Preference Disaggregation. Variations on the classical MCDM/A methodologies have been addressed over the years; examples include the consideration of linguistic and fuzzy variables [24-26] and the incorporation of preference disaggregation for specific methods [20, 27].

Multicriteria methodologies are used in a vast variety of problems and fields of action. Doumpos et al. [28] draw special attention to areas such as medicine, human resources, marketing, finance, and energy management. Other examples include civil construction [29], evaluating suppliers in supply chains [30], portfolio decision analysis [31], assessing human resource skills management [32], public safety [33], jobsatisfaction [34], location selection [35], and ranking credit risk algorithms. The use of MCDM/A for Risk Management decisions has been increasing lately. A systematic literature review was presented in [36], and the main criterion areas found included safety, financial, environmental, social, and infrastructure. A hybrid FMEA model is applied to evaluate the risk of superficial water gasification systems [26], considering subjective and objective weights and linguistic terms. An MCDM/A framework that also considers linguistic variables and incorporates prospect theory is proposed in [37] and applied to risk analysis of energy performance contracting.

Regarding the field of finance, an important use of multicriteria sorting methods is related to evaluating credit risk for countries (sovereign risk) and organizations, and in many cases the risk of bankruptcy is also assessed. Zopounidis et al. [38] present a review of the literature that addresses $\mathrm{MCDA} / \mathrm{M}$ in finance, credit risk, and country risk being two prominent fields in this review. Kosmidou et al. [14] present applications of several studies involving the assessment of country risk with the presentation of different decision analysis techniques. Other applications in finance involve commercial bank acquisition environments [39] and evaluations of Brazilian investment funds [25].

Doumpos et al. [40] apply a sorting approach based on multicriteria decision concepts and mathematical programming, called the Multi-Hierarchical Hierarchical Discrimination Method (M.H.DIS), to sort countries into four levels of risk. In this application, countries are initially divided into categories that are defined according to the income level of the alternatives: a high-income economy, a middlehigh income economy, a low-middle income economy, and 
a low-income economy. Greco et al. [41] evaluated, by using decision rules in a learning approach via Rough Sets, the risk of investing in a set of 52 countries, based on 27 indicators.

$\mathrm{Hu}$ and Chen [42] proposed a multicriteria outranking method, based on the formulation of PROMETHEE II, and applied it to predict whether businesses would go bankrupt. The model that they put forward uses agreement and disagreement indices that evaluate the degree to which each alternative of the model outranks and is outranked by all the alternatives/reference profiles defined in all categories. Another sorting approach based on the PROMETHEE II method is presented by Doumpos and Zopounidis [20], with an application focused on assessing the credit risk of a group of companies belonging to the portfolio of a Greek bank. The credit quality of organizations was also analyzed by [43] using the ELECTRE TRI-nC method, in an application that focused on corporate credit bonds.

Yu et al. [44] propose a multicriteria decision support model, to be applied in the finance sector, based using a methodology that aggregates GDM (Group Decision Making), fuzzyfication, and artificial intelligence techniques. They apply the model to assess the credit risk associated with loans made by financial institutions to their clients, and ultimately sort clients' applications as to whether or not they are acceptable to the banks. Zhang et al. [45] present the KFPMCOC, based on MCOC (Multicriteria Optimization Classifier), kernel, fuzzyfication, and penalty factors, and apply it in the context of assessing credit risk. Corazza et al. [46] use a multicriteria decision support approach to assess the quality of banks' potential clients, among a large group of Italian SMEs, in relation to the clients' ability to comply with financial agreements that they will enter into.

Credit risk assessment through MCDM/A approaches is a relevant and nowadays research topic according to the recent developments in the literature. The use of sorting methods is indicated for different kinds of problems regarding this topic, as it is common to categorize issuers of debt instruments into levels of risk, as found in [43]. More specifically, the 2008 global financial crisis and the sovereign debt crisis have motivated studies regarding the impact of sovereign credit ratings [9]. Although applications of country risk evaluations can be found in literature, as presented by [14, 40], this still is a relevant topic to be developed. Thus, this paper adds new features to solve this problem by structuring a new decision model by adding new criteria to enrich the analysis considering different criteria and deploying a PROMETHEE-based sorting approach that enables a different preference structure to be represented through a disaggregation approach.

\section{Materials and Methods}

In their study, Brans and Vincke [47] introduced the principles of the PROMETHEE family of methods, by presenting the PROMETHEE I and PROMETHEE II versions. Behzadian et al. [48] define PROMETHEE (Preference Ranking Organization Method for Enriching Evaluations) as an outranking method that works with ordering and selecting a finite set of alternatives based on criteria, which are often conflicting. Algorithm 1 is an algorithm for using PROMETHEE II, adapted from [48].

Doumpos and Zopounidis [20] present an adaptation of a multicriteria decision model that works with structures similar to those of the PROMETHEE II method, and the proposal is adapted to the sorting problematic and to preference disaggregation. Initially, examples of assignments are found that are based on obtaining parameters and for sorting the other alternatives. Thus, for each alternative to be assigned, the pairwise comparisons are made in relation to reference alternatives, which are predefined for each category of problem. To obtain the necessary parameters for the sorting process, such as preference functions and criteria weights, the authors propose using linear programming, modeling each preference function $p_{j}$ as parts of a linear function. The model applied in this study is presented below and more specific details about the algorithm of the method can be found in [20].

The problem is to sort a set of alternatives into 3 ordered categories such as $C_{1}>C_{2}>C_{3}$. As a basis for the pairwise comparisons proposed in the model, this study used three reference countries for each of the categories. In a situation of a three-category problem, two dichotomous cases are analyzed [20]. For the purposes of being better able to visualize and organize these cases for further analysis, they are explained below. In the following formulation $m_{1}, m_{2}$, and $m_{3}$ represent the quantities of reference alternatives of categories $C_{1}, C_{2}$, and $C_{3}$, respectively.

(i) Dichotomous Case 1. Initially, for each alternative $x_{k}$, an analysis is made of the input flows coming from only the reference alternatives $x_{i}$ of category $C_{1}$ and the output flows to the reference alternatives $x_{i}$ of categories $C_{2}$ and $C_{3}$. If the net flow is greater than the cut-off point $\mathrm{b}_{1}$, the alternative $x_{k}$ is allocated to the category $C_{1}$. Otherwise, the alternative is analyzed in dichotomous case 2.

$$
f_{k 1}=\frac{1}{\left(m_{2}+m_{3}\right)} \sum_{x i \in C 2 \cup C 3} P_{k i}-\frac{1}{m_{1}} \sum_{x i \in C 1} P_{i k}
$$

(ii) Dichotomous Case 2. For each alternative $x_{k}$, the input flows from the reference alternatives belonging to categories $C_{1}$ and $C_{2}$ and the output flows for the reference alternatives belonging to category $\mathrm{C}_{3}$ are analyzed. If the net flow is greater than the cut-off point $b_{2}$, the alternative $x_{k}$ is allocated to category $C_{2}$. Otherwise, the alternative is allocated to $C_{3}$.

$$
f_{k 2}=\frac{1}{m_{3}} \sum_{x i \in \mathrm{C} 3} P_{k i}-\frac{1}{\left(m_{1}+m_{2}\right)} \sum_{x i \in C 1 \cup C 2} P_{i k}
$$

The linear programming model is then applied in order to minimize the sum of error variables, in accordance with Doumpos and Zopounidis [20].

$\min E$

$$
=\frac{1}{m_{1}}\left(\sum_{x_{i} \in X \cap C_{1}} e_{i, 1}+e_{i, 2}\right)
$$


Step 1. Determine the deviations based on pairwise comparisons.

$$
d_{j}^{a b}=g_{j}\left(x_{a}\right)-g_{j}\left(x_{b}\right)
$$

Where $d_{j}^{a b}$ denotes the difference between the consequences of the alternatives $x_{a}$ and $x_{b}$ for each criterion $j$.

Step 2. Apply the preference function.

$$
p_{j}\left(x_{a} x_{b}\right)= \begin{cases}0 & \text { if } d_{j}^{a b}<0 \\ h_{j}\left(d_{j}^{a b}\right) & \text { if } d_{j}^{a b} \geq 0\end{cases}
$$

Where $p_{j}\left(x_{a} x_{b}\right)$ denotes the preference of alternative of $x_{a}$ over the alternative $x_{b}$, for each criterion $\mathrm{j}$, based on the deviation $d_{j}^{a b}=g_{j}\left(x_{a}\right)-g_{j}\left(x_{b}\right)$.

Step 3. Calculate the outranking degree.

$$
P_{a b}=\sum_{j=1}^{n} w_{j} p_{j}\left(x_{a} x_{b}\right)
$$

When the outranking degree $P_{a b}$ of the alternative $x_{a}$ over the alternative $x_{b}$ is the weighted sum of the set of preference functions of the form $p_{j}\left(x_{a} x_{b}\right)$ because of the weights of the criteria, represented by $w_{j}$.

Step 4. Calculate the positive and negative flows regarding the partial ranking of PROMETHEE I

$$
\begin{aligned}
& f_{a}^{+}=\frac{1}{n-1} \sum_{x b \in A} P_{a b} \\
& f_{a}^{-}=\frac{1}{n-1} \sum_{x b \in A} P_{b a}
\end{aligned}
$$

Where $f_{a}^{+}$e $f_{a}^{-}$denote, respectively, the negative and positive flows of alternative $x_{a}$.

Step 5. Calculate the net flow with regard to the complete order of PROMETHEE II

Where $f_{a}$ denotes the net flow with regard to alternative $x_{a}$

$$
f_{a}=f_{a}^{+}-f_{a}^{-}
$$

Algorithm 1: Routine for PROMETHEE II.

$$
\begin{aligned}
& +\frac{1}{m_{2}}\left(\sum_{x_{i} \in X \cap C_{2}} e_{i, 1}+e_{i, 2}\right) \\
& +\frac{1}{m_{3}}\left(\sum_{x_{i} \in X \cap C_{3}} e_{i, 1}+e_{i, 2}\right)
\end{aligned}
$$

$$
\begin{aligned}
& \text { Subject to: } f_{i 1}+e_{i, 1} \geq b_{1}+a, \quad \forall x_{i} \in X \cap C_{1} \\
& f_{i 2}+e_{i, 2} \geq b_{2}+a, \quad \forall x_{i} \in X \cap C_{1} \\
& f_{i 1}-e_{i, 1} \leq b_{1}-a, \quad \forall x_{i} \in X \cap C_{2} \\
& f_{i 2}+e_{i, 2} \geq b_{2}+a, \quad \forall x_{i} \in X \cap C_{2} \\
& f_{i 1}-e_{i, 1} \leq b_{1}-a, \quad \forall x_{i} \in X \cap C_{3} \\
& f_{i 2}-e_{i, 2} \leq b_{2}-a, \quad \forall x_{i} \in X \cap C_{3} \\
& \sum_{j=1}^{n} \sum_{t=1}^{S_{j}} h^{\prime}{ }_{j t}=1 \\
& e_{i, t} \geq 0 \\
& w_{j} \geq 0 \text {, }
\end{aligned}
$$

$$
\forall i, t, j
$$

Equation (9) consists of the objective function, which minimizes the sum of error variables that may be necessary to make the assignments of the reference alternatives match their respective previous allocations.

Equations (10) to (15) determine exactly how this matching of allocations is performed, based on the decision rules set out in the two dichotomous cases explained above. For example, a reference alternative $x_{i}$ of category $C_{2}$ must, in dichotomous case 1 , obtain a flow fil that is lower than the cut-off point $b_{1}$ (see (12)) and, for dichotomous case 2 , it must obtain a flow $f_{i 2}$ higher than the cut-off point $b_{2}$ (see (13)).

Equation (16) defines the construction of the piecewise linear function which is directly related to calculating the weights for the criteria $w_{j}$, thus ensuring that their sum is one. Equation (17) represents the nonnegativity constraint for the decision variables representing the $w_{j}$ weights and the $e_{i t}$ errors.

\section{Sovereign Credit Risk Assessment Model Based on a PROMETHEE Approach}

There are several aspects that should be considered in sovereign credit risk rating. The concerns about this issue were raised especially after the subprime crisis as a relevant problem to be addressed. Therefore, this problem consists of sorting a set of sovereign bonds according to their level of risk. 


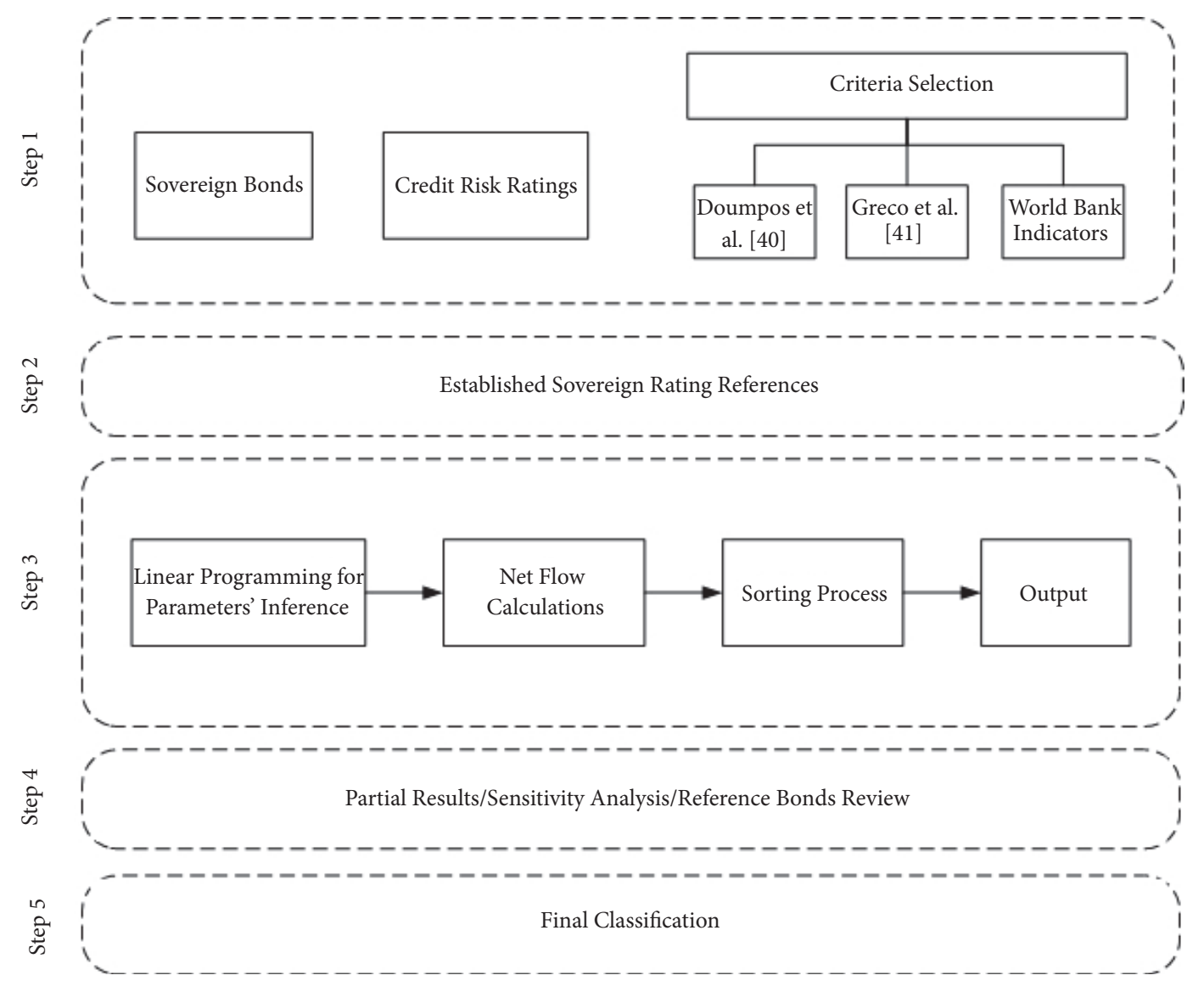

FIGURE 1: Sovereign credit risk assessment model based on a PROMETHEE approach.

Given the number of aspects to be considered and the subjectivity involved when rating these bonds, an MCDM/A model was proposed to provide a better understanding of the decision process and its results in terms of final rating.

When structuring such a decision model the way how objective and subjective information are used for the risk assessment is explicit, so the final result can be justified and criticized if there would be any inconsistency along the process. Thus, the model enables verifying how the final rating was achieved and if necessary justify its parameterization. The steps of the MCDM/A model are illustrated in Figure 1 and detailed subsequently.

Step 1 of the model consists of the problem definition. In this step, the sovereign bonds to be considered are selected to build a set of alternatives. Also, the categories of risk are defined and a search on credit risk rating systems is performed. Furthermore, the criteria of the model are defined to build the set of criteria.

In the second step, the reference set is defined. Usually, the reference alternatives for preference disaggregation approaches are established by expert(s) or $\mathrm{DM}(\mathrm{s})$, which may be assisted by a facilitation process. These reference alternatives are alternatives that would have an obvious rating or easier for an expert or DM to rate, while other sovereign rating models may be used as well to support this process. Another option is to define the set of reference alternatives randomly fulfilling a minimum number of reference alternatives to each class.

In the third step, an MCDM/A sorting model based on indirect elicitation of preferences is considered. First, the set of reference alternatives is used for the inference of parameters based on a Linear Programming Problem (LPP). Second, the Net Flows are calculated considering the method designed by [20], as shown in the previous section.

In Step 4, the DM may be supported by an analyst to verify the consistency of the results and, if necessary, define which changes should be made to the set of reference alternatives or if any constraint should be added to the LPP for inferring the model parameters. Afterwards, Step 5 defines the final classification and further analysis can be made, such as comparing the results with well-known risk ratings, such as the Moody's and Standard \& Poor's classifications to understand the differences among results, which are usually due to subjective aspects considered and interpreted by these agencies experts that may fail as recently exposed [4-8].

A search for possible financial indicators was carried out and nine criteria that the World Bank measures and publishes were collected. Some examples of financial indicators used to evaluate countries can be found in literature [40, 41]. The criteria chosen and used in the model are shown in Table 1.

To validate the model proposed in this paper, a grouping into three categories of risk was proposed based on the ratings 
TABLE 1: Criteria selected for the model and their preference direction.

\begin{tabular}{lcc}
\hline & CRITERIA FOR THE MODEL & \\
\hline 1 & GDP per capita (current US\$) & Increasing \\
\hline 3 & Exports of goods and services (\% of GDP) & Increasing \\
\hline 4 & Gross savings (\% of GDP) & Increasing \\
\hline 5 & Foreign direct investment, net inflows (BoP, current US\$) & Increasing \\
\hline 6 & Total reserves (includes gold, current US\$) & Increasing \\
\hline 7 & GNI per capita, Atlas method (current US\$) & Increasing \\
\hline 8 & Lending interest rate (\%) & Increasing \\
\hline 9 & Real interest rate (\%) & Decreasing \\
\hline
\end{tabular}

TABLE 2: Conversion process for the initial allocations to three risk categories.

\begin{tabular}{|c|c|c|}
\hline Category & Moody's Ratings & $\begin{array}{c}\text { Standard \& } \\
\text { Poor's Ratings }\end{array}$ \\
\hline \multirow{7}{*}{$C_{1}$} & Aaa & AAA \\
\hline & Aal & $\mathrm{AA}+$ \\
\hline & $\mathrm{Aa} 2$ & AA \\
\hline & $\mathrm{Aa} 3$ & AA- \\
\hline & $\mathrm{A} 1$ & $\mathrm{~A}+$ \\
\hline & A2 & A \\
\hline & $\mathrm{A} 3$ & A- \\
\hline \multirow{3}{*}{$C_{2}$} & Baal & $\mathrm{BBB}+$ \\
\hline & $\mathrm{Baa} 2$ & $\mathrm{BBB}$ \\
\hline & Baa3 & BBB- \\
\hline \multirow{6}{*}{$C_{3}$} & $\mathrm{Bal}$ & $\mathrm{BB}+$ \\
\hline & $\mathrm{Ba} 2$ & $\mathrm{BB}$ \\
\hline & $\mathrm{Ba} 3$ & BB- \\
\hline & $\mathrm{B} 1$ & $\mathrm{~B}+$ \\
\hline & B2 & B \\
\hline & B3 & B- \\
\hline$C_{3}$ & $\begin{array}{c}\text { Caal } \\
\mathrm{Caa} 2 \\
\mathrm{Caa} 3 \\
\mathrm{Ca} \\
\mathrm{C}\end{array}$ & $\begin{array}{c}\mathrm{CCC}+ \\
\text { CCC } \\
\text { CCC- } \\
\text { CC } \\
\text { C } \\
\text { D }\end{array}$ \\
\hline
\end{tabular}

of credit agencies at three levels of risk. To this end, countries with a rating of $\mathrm{A}$ or higher (associated with the lowest risks) were allocated to category $C_{1}$, countries with a triple rating $B$ of the agencies were allocated to category $C_{2}$, and the other countries with a rating of double $B$ or lower were allocated to category $C_{3}$. Whenever there were divergences in the ratings of the agencies, the lowest ratings were considered, i.e., the worst scenario for the country. Table 2 presents the details of the conversion.

Choosing the reference alternatives was based on the ratings of Moody's and Standard \& Poor's for the year 2014. In addition, 2014 was also used as the data source for the nine criteria of the model. Thus, the countries chosen were those that, for 2014, have at least one of the ratings and for which data for the nine criteria were available. Thus, data for a total of 45 countries were used in the multicriteria sorting model.

As part of analyzing the results of the model, comparisons were made between the assignments of the countries from applying the model and the assignments based on the ratings of the two risk agencies. Regarding the results based on the agencies, the alternatives were allocated to the categories starting with the worst scenario between the two agencies' allocations, thus maintaining a conservative profile. Thus, in a preliminary way and prior to applying the sorting model, the 45 countries were allocated to the three categories proposed. The countries, their ratings, and their allocations are listed in Table 3 .

Of the 45 countries analyzed in the model, nine of them were rated by only one rating agency in 2014. In total, 41 countries have Standard \& Poor's ratings and 40 countries have Moody's ratings. Of the 36 countries analyzed by both agencies that year, in only two cases do the agency ratings allocate a country to different categories. This is for Mexico, allocated to $C_{1}$ by Moody's and to $C_{2}$ by Standard \& Poor's, and for Bulgaria, allocated to $C_{2}$ by Moody's and to $C_{3}$ by Standard \& Poor's.

To illustrate the use of the proposed model through a numerical application, a set of reference alternatives was chosen randomly to fulfill three reference countries per category. To guarantee consistency and to avoid bias on the selection, several random sets of reference alternatives have been tested, and all indicated similar results when compared to the established ratings.

Furthermore, to avoid overloading the results with additional redundant information, the results for only one set of reference alternatives are presented, and the countries chosen at random for each category are presented in Table 4 .

The advantage of using a preference disaggregation approach is that when it is not possible to elicit DMs' preferences directly by the classical approaches, reference examples may be used to overcome situations when the DM is not able to indicate specific parameters or not available to participate into a long elicitation process because of time restrictions [27]. Thus, a preference disaggregation model should be capable of inferring precise parameters without strong requirements. 
TABLE 3: Initial allocation for the alternatives based on their ratings.

\begin{tabular}{|c|c|c|c|}
\hline Country & S\&P & Moody's & $\mathrm{Cl}$ \\
\hline Australia & AAA & Aaa & $C_{1}$ \\
\hline Czech Republic & AA- & $\mathrm{A} 1$ & $C_{1}$ \\
\hline Korea, Rep. & $\mathrm{A}+$ & $\mathrm{Aa3}$ & $\overline{C_{1}}$ \\
\hline Canada & AAA & Aaa & $\overline{C_{1}}$ \\
\hline United Kingdom & AAA & Aal & $C_{1}$ \\
\hline Estonia & AA- & $\mathrm{A} 1$ & $\overline{C_{1}}$ \\
\hline Chile & AA- & $\mathrm{Aa3}$ & $\overline{C_{1}}$ \\
\hline Israel & $\mathrm{A}+$ & $\mathrm{A} 1$ & $\overline{C_{1}}$ \\
\hline Kuwait & AA & $\mathrm{Aa} 2$ & $\overline{C_{1}}$ \\
\hline Qatar & AA & $\mathrm{Aa} 2$ & $C_{1}$ \\
\hline Singapore & AAA & Aaa & $C_{1}$ \\
\hline Brazil & BBB- & Baa2 & $\mathrm{C}_{2}$ \\
\hline Colombia & $\mathrm{BBB}$ & Baa2 & $\mathrm{C}_{2}$ \\
\hline Italy & BBB- & Baa2 & $\mathrm{C}_{2}$ \\
\hline Mexico & $\mathrm{BBB}+$ & $\mathrm{A} 3$ & $\mathrm{C}_{2}$ \\
\hline Romania & BBB- & Baa3 & $C_{2}$ \\
\hline Uruguay & $\mathrm{BBB}$ & Baa2 & $\mathrm{C}_{2}$ \\
\hline Azerbaijan & BBB- & Baa3 & $\mathrm{C}_{2}$ \\
\hline Bahamas, The & $\mathrm{BBB}$ & & $\mathrm{C}_{2}$ \\
\hline Indonesia & & Baa3 & $\mathrm{C}_{2}$ \\
\hline India & BBB- & Baa3 & $\overline{C_{2}}$ \\
\hline Philippines & BBB & Baa2 & $\mathrm{C}_{2}$ \\
\hline Russian Federation & BBB- & Baa3 & $\mathrm{C}_{2}$ \\
\hline Thailand & $\mathrm{BBB}+$ & Baal & $\mathrm{C}_{2}$ \\
\hline South Africa & BBB- & Baa2 & $\mathrm{C}_{2}$ \\
\hline Ukraine & CCC- & Caa3 & $C_{3}$ \\
\hline Jamaica & B- & Caa3 & $C_{3}$ \\
\hline Montenegro & $\mathrm{B}+$ & $\mathrm{Ba} 3$ & $C_{3}$ \\
\hline Hungary & BB & & $C_{3}$ \\
\hline Guatemala & $\mathrm{BB}$ & Bal & $C_{3}$ \\
\hline Costa Rica & $\mathrm{BB}$ & & $C_{3}$ \\
\hline Argentina & $\mathrm{C}$ & Caal & $C_{3}$ \\
\hline Albania & $\mathrm{B}$ & $\mathrm{B} 1$ & $C_{3}$ \\
\hline Bangladesh & BB- & $\mathrm{Ba} 3$ & $C_{3}$ \\
\hline Bulgaria & $\mathrm{BB}+$ & Baa2 & $C_{3}$ \\
\hline Bosnia and Herzegovina & $\mathrm{B}$ & B3 & $C_{3}$ \\
\hline Belarus & B- & B3 & $C_{3}$ \\
\hline Bolivia & $\mathrm{BB}$ & & $C_{3}$ \\
\hline Georgia & BB- & $\mathrm{Ba3}$ & $C_{3}$ \\
\hline Kenya & & B1 & $C_{3}$ \\
\hline Moldova & & B3 & $C_{3}$ \\
\hline Macedonia, FYR & BB- & & $C_{3}$ \\
\hline Nicaragua & & B3 & $C_{3}$ \\
\hline Egypt, Arab Rep. & $\mathrm{B}-$ & Caal & $C_{3}$ \\
\hline Congo, Dem. Rep. & B- & B3 & $C_{3}$ \\
\hline
\end{tabular}

After the process of defining the decision criteria, categories, alternatives, and the set of reference alternatives, the MCDM/A method proposed by [20] and briefly explained
TABLE 4: Set of reference alternatives.

\begin{tabular}{lcc}
\hline Category $C_{1}$ & Category $C_{2}$ & Category $C_{3}$ \\
\hline Canada & India & Montenegro \\
\hline Estonia & Thailand & $\begin{array}{c}\text { Bosnia and } \\
\text { Herzegovina }\end{array}$ \\
\hline United & Italy & Georgia \\
Kingdom & & \\
\hline
\end{tabular}

TABLE 5: Criteria weights obtained with the linear programming model.

\begin{tabular}{lc}
\hline Criterion & Weight \\
\hline $\mathbf{1}$ & 0.0922 \\
$\mathbf{2}$ & 0.2317 \\
$\mathbf{3}$ & 0.1142 \\
$\mathbf{4}$ & 0.0839 \\
$\mathbf{5}$ & 0.0667 \\
$\mathbf{6}$ & 0.0789 \\
$\mathbf{7}$ & 0.0907 \\
$\mathbf{8}$ & 0.1007 \\
$\mathbf{9}$ & 0.141 \\
\hline
\end{tabular}

in the prior section was applied. The LPP (see (9)-(17)) was used to infer the parameters for the PROMETHEE-based classification. In summary, 45 alternatives were considered. From the initial set, nine alternatives were chosen as a reference for the disaggregation model, and the remaining 38 were allocated to three different risk categories. The results are exposed and discussed in the next section.

\section{Results and Discussion}

Table 5 shows the weights that were calculated for each criterion from the algorithm of the sorting method with a PROMETHEE approach [20]. As explained earlier, weights are calculated using linear programming in accordance with the choice of the set of reference alternatives. On analyzing the table, the weights obtained for the best match of the reference set in the categories previously determined can be seen. Only Criterion 2, which represents the countries' exports as a percentage of GDP, received a weight of over $20 \%$. Criterion 3 also had a very noteworthy result, being this related to the country's gross savings.

Table 6 presents the results of the multicriteria sorting model. In this table, reference countries are indicated by the abbreviation $R E F(C j)$, where $j$ assumes the values 1,2 , or 3 and indicates the country's reference category.

Statistical analyzes involving the percentage of similarity between the results obtained from the sorting model and the results from the ratings were performed. Table 7 presents the results of these comparisons. In this table, the column with the term $\mathrm{N}$ represents the total number of countries allocated for each category based on the ratings of the risk agencies (Table 2). These numbers are obtained by subtracting the number of countries of reference from the total number of countries allocated to the categories. Thus, as 45 countries 
TABLE 6: Final allocation related to the application of the multicriteria sorting model.

\begin{tabular}{|c|c|}
\hline Countries & Result \\
\hline Australia & $C_{1}$ \\
\hline Czech Republic & $C_{1}$ \\
\hline Korea, Rep. & $C_{1}$ \\
\hline Canada & $\operatorname{REF}\left(C_{1}\right)$ \\
\hline United Kingdom & $\operatorname{REF}\left(C_{1}\right)$ \\
\hline Estonia & $\operatorname{REF}\left(C_{1}\right)$ \\
\hline Chile & $C_{2}$ \\
\hline Israel & $C_{2}$ \\
\hline Kuwait & $C_{1}$ \\
\hline Qatar & $C_{1}$ \\
\hline Singapore & $C_{1}$ \\
\hline Brazil & $C_{2}$ \\
\hline Colombia & $C_{3}$ \\
\hline Italy & $\operatorname{REF}\left(C_{2}\right)$ \\
\hline Mexico & $\mathrm{C}_{2}$ \\
\hline Romania & $C_{2}$ \\
\hline Uruguay & $C_{3}$ \\
\hline Azerbaijan & $C_{3}$ \\
\hline Bahamas, The & $C_{2}$ \\
\hline Indonesia & $C_{2}$ \\
\hline India & $R E F\left(C_{2}\right)$ \\
\hline Philippines & $C_{2}$ \\
\hline Russian Federation & $C_{2}$ \\
\hline Thailand & $R E F\left(C_{2}\right)$ \\
\hline South Africa & $C_{2}$ \\
\hline Ukraine & $C_{3}$ \\
\hline Jamaica & $C_{3}$ \\
\hline Montenegro & $\operatorname{REF}\left(C_{3}\right)$ \\
\hline Hungary & $C_{1}$ \\
\hline Guatemala & $C_{3}$ \\
\hline Costa Rica & $C_{3}$ \\
\hline Argentina & $\mathrm{C}_{2}$ \\
\hline Albania & $C_{3}$ \\
\hline Bangladesh & $C_{3}$ \\
\hline Bulgaria & $C_{2}$ \\
\hline Bosnia and Herzegovina & $\operatorname{REF}\left(C_{3}\right)$ \\
\hline Belarus & $C_{2}$ \\
\hline Bolivia & $C_{3}$ \\
\hline Georgia & $R E F\left(C_{3}\right)$ \\
\hline Kenya & $C_{3}$ \\
\hline Moldova & $\mathrm{C}_{3}$ \\
\hline Macedonia, FYR & $\mathrm{C}_{2}$ \\
\hline Nicaragua & $C_{3}$ \\
\hline Egypt, Arab Rep. & $C_{3}$ \\
\hline Congo, Dem. Rep. & $C_{3}$ \\
\hline
\end{tabular}

were allocated in Table 3 and nine of these were used in the model as reference countries, the total number of countries
TABLE 7: Similarity between the final allocation provided by the model and the initial allocation based on ratings.

\begin{tabular}{lccr}
\hline & $\mathrm{N}$ & \multicolumn{2}{c}{ Adherence } \\
\hline $\boldsymbol{C}_{\boldsymbol{1}}$ & 8 & 6 & $75.00 \%$ \\
\hline $\boldsymbol{C}_{2}$ & 11 & 8 & $72.73 \%$ \\
\hline $\boldsymbol{C}_{3}$ & 17 & 12 & $70.59 \%$ \\
\hline Total & $\mathbf{3 6}$ & $\mathbf{2 6}$ & $\mathbf{7 2 . 2 2 \%}$ \\
\hline
\end{tabular}

TABLE 8: Alternatives with different allocations for each category considered in the application.

\begin{tabular}{lcc}
\hline Ratings & Country & MCDM/A Model \\
\hline$C_{1}$ & Chile & $C_{2}$ \\
& Israel & $C_{2}$ \\
\hline \multirow{2}{*}{$C_{2}$} & Colombia & $C_{3}$ \\
& Azerbaijan & $C_{3}$ \\
& Uruguay & $C_{3}$ \\
\multirow{4}{*}{$C_{3}$} & Hungary & $C_{1}$ \\
& Argentina & $C_{2}$ \\
& Bulgaria & $C_{2}$ \\
& Belarus & $C_{2}$ \\
\hline
\end{tabular}

allocated by the model was 36 . Table 7 shows the number and percentage of countries that are allocated by the model similarly to the allocations in Table 3 , for each of the three categories.

The results of Table 7 demonstrate that the model obtained percentages of high similarity, thereby exceeding $70 \%$ in the total of the allocations and also after analyzing each category individually. Taking into account the countries that the agencies allocated to $C_{1}$, the highest such percentage reached by the model was $75 \%$.

On analyzing the countries that the agencies allocated to $C_{2}$, the model sorted three countries differently: Colombia, Azerbaijan, and Uruguay. In the three cases, the multicriteria model sorts these countries as category $C_{3}$. Thus, it can be seen that these countries cannot obtain enough advantages over the reference countries to overcome the cut-off points $b_{1}$ and $b_{2}$ in their respective dichotomous cases.

On analyzing the results by category, note that the lowest percentage of similarity is found in category $C_{3}$. Of the total of 17 countries allocated to this category based on the risk agencies' ratings, the model sorted 12 of them similarly. This indicates that countries that originally received low ratings from the rating agencies, when compared to the reference set, have some advantage in the performance of the criteria and thus the model allocates them to higher categories. Table 8 illustrates the countries that were allocated differently by the multicriteria sorting model.

Among the reasons that may cause the assignments of countries allocated to $C_{3}$ to be changed, what stands out is the great variety of countries that have been allocated to this category, as shown in Table 3. As previously described, category $C_{3}$ encompasses a greater variety of ratings, involving all countries that do not have an investment grade. In addition, 
countries may lose the agencies' investment grade, thus dropping down to category $C_{3}$, because issues concerning qualitative indices are involved that are not present in the set of selected criteria. For example, political situations in countries, such as corruption and clashes over land, although very important for defining a country's sovereign risk, were not incorporated into the model due to the difficulty in obtaining this information in a standardized way for a large number of countries.

\section{Conclusions}

The results of the linear programming applied in the model indicated, initially, the weights of the criteria used that best defined the assignments for the chosen set of reference. For this set and thus later for the complete model an indicator of exports of goods and services had a greater degree of importance in the final result in relation to the other indicators. In relation to the allocations, the results obtained demonstrate a good applicability of the multicriteria sorting method used in the context of sovereign risk. The reference set obtained good percentages of similarity in the total of allocations in relation to the agencies, with values that exceeded $70 \%$ of similarity in each of the categories considered.

Given the great diversity of countries and the variety of aspects that can influence their performances in economic indicators, the alternatives of category $C_{3}$ may have large differences in performance under one criterion. This may be one of the causes for five countries to be sorted differently in relation to the assignments arising from the ratings. In this scenario, Hungary stands out, which was allocated by the ratings to category $C_{3}$ and was allocated by the model in category $C_{1}$. Another reason that may lead to differences in allocations is the lack of qualitative criteria in the model. The absence of subjective criteria, such as political risk, can be considered as a limitation of the model.

In this respect, a possible recommendation/improvement for future work concerns incorporating qualitative indices into the set of criteria of the model, e.g., an indicator of a country's political risk. Another test that can be carried out in future research studies is to apply the model in a context of four categories: $C_{1}>C_{2}>C_{3}>C_{4}$. On doing so, a portion of the ratings corresponding to category $C_{3}$ would correspond to the additional category. In addition, tests with different reference combinations can be performed and compared to each other.

It is important to emphasize that, in this research, decision makers played no part in choosing reference countries. The choices were made in a random manner and were oriented only by the assignments of the agencies present in Table 2. When working with a decision maker, on the other hand, the choice of reference set is free, and thus, an alternative can be chosen that is allocated to category $C_{2}$ of Table 3 , such as Italy, for example, as reference country of category $C_{1}$.

In sum, the paper contributes to the literature by modeling the problem of sorting sovereign risk based on real data and by applying a multicriteria decision method that, by using only nine reference countries and entirely objective criteria, was able to obtain ratings similar to those of international risk agencies. In this context, a model with greater methodological clarity and objectivity such as the one proposed can help investors and serve as an additional tool to help them make investments. Thus, this paper proposes an objective approach to assess sovereign credit risk rating, which is considered a relevant topic in the literature due to misperceptions and arbitrary valuation of subjective aspects as experienced after subprime crisis [4-8].

\section{Data Availability}

The data used to support the findings of this study are available from the corresponding author upon request.

\section{Conflicts of Interest}

The authors declare that there are no conflicts of interest regarding the publication of this article.

\section{Acknowledgments}

This study was partially funded by $\mathrm{CNPq}$ and Facepe for which the authors are grateful.

\section{References}

[1] M. M. Mousavi and J. Ouenniche, "Multi-criteria ranking of corporate distress prediction models: empirical evaluation and methodological contributions," Annals of Operations Research, pp. 1-34, 2018.

[2] O. Canuto, P. F. D. Dos Santos, and P. C. De sá Porto, "Macroeconomics and sovereign risk ratings," Journal of International Commerce, Economics and Policy, vol. 3, no. 2, pp. 1-25, 2012.

[3] X. Guo, Z. Zhu, and J. Shi, "A Corporate Credit Rating Model Using Support Vector Domain Combined with Fuzzy Clustering Algorithm," Mathematical Problems in Engineering, vol. 2012, Article ID 302624, 20 pages, 2012.

[4] C. Salvador, J. M. Pastor, and J. Fernández de Guevara, "Impact of the subprime crisis on bank ratings: The effect of the hardening of rating policies and worsening of solvency," Journal of Financial Stability, vol. 11, no. 1, pp. 13-31, 2014.

[5] T. F. Rötheli, "Causes of the financial crisis: Risk misperception, policy mistakes, and banks' bounded rationality," Journal of Socio-Economics, vol. 39, no. 2, pp. 119-126, 2010.

[6] L. B. Andersen, D. Häger, S. Maberg, M. Næss, and M. Tungland, "The financial crisis in an operational risk management context-A review of causes and influencing factors," Reliability Engineering \& System Safety, vol. 105, pp. 3-12, 2012.

[7] T. Bellotti, R. Matousek, and C. Stewart, "Are rating agencies' assignments opaque? Evidence from international banks," Expert Systems with Applications, vol. 38, no. 4, pp. 4206-4214, 2011.

[8] T. Jiang, M. Zhou, B. Shen et al., "Dynamics in Bank Crisis Model," Mathematical Problems in Engineering, vol. 2015, Article ID 378463, 5 pages, 2015.

[9] H. Almeida, I. Cunha, M. A. Ferreira, and F. Restrepo, "The Real Effects of Credit Ratings: The Sovereign Ceiling Channel," Journal of Finance, vol. 72, no. 1, pp. 249-290, 2017.

[10] L. Ping and W. Xiaowu, "Empirical pricing of Chinese Defaultable Bonds Based on the Incomplete Information Model," 
Mathematical Problems in Engineering, vol. 2014, Article ID 286739, 5 pages, 2014.

[11] A. Sensoy, D. K. Nguyen, A. Rostom, and E. Hacihasanoglu, "Dynamic integration and network structure of the EMU sovereign bond markets," Annals of Operations Research, pp. 118,2018

[12] Standard \& Poor's, Sovereign Rating Methodology, 2017.

[13] S. Hoti and M. McAleer, "An Empirical Assessment of Country Risk Ratings and Association Models," Journal of Economic Surveys, vol. 18, no. 4, pp. 539-550, 2003.

[14] K. Kosmidou, M. Doumpos, and C. Zopounidis, Country Risk Evaluation: Methods and Applications, vol. 15, Springer, 2008.

[15] B. Roy, Multicriteria Methodology for Decision Aiding, Kluwer Academic Publishers, 1996.

[16] L. G. de Oliveira Silva and A. T. de Almeida-Filho, "A new PROMETHEE-based approach applied within a framework for conflict analysis in Evidence Theory integrating three conflict measures," Expert Systems with Applications, vol. 113, pp. 223232, 2018.

[17] E. Fernández, J. R. Figueira, and J. Navarro, "An interval extension of the outranking approach and its application to multiplecriteria ordinal classification," Omega (United Kingdom), pp. 110, 2018.

[18] E. Fernández, J. R. Figueira, J. Navarro, and B. Roy, "ELECTRE TRI-nB: A new multiple criteria ordinal classification method," European Journal of Operational Research, vol. 263, no. 1, pp. 214-224, 2017.

[19] A. S. Costa, J. R. Figueira, and J. Borbinha, "A multiple criteria nominal classification method based on the concepts of similarity and dissimilarity," European Journal of Operational Research, vol. 271, no. 1, pp. 193-209, 2018.

[20] M. Doumpos and C. Zopounidis, "A multicriteria classification approach based on pairwise comparisons," European Journal of Operational Research, vol. 158, no. 2, pp. 378-389, 2004.

[21] N. Rangel-Valdez, E. Fernandez, L. Cruz-Reyes, C. GomezSantillan, G. Rivera, and R. Florencia, "Robustness Analysis of an Outranking Model Parameters' Elicitation Method in the Presence of Noisy Examples," Mathematical Problems in Engineering, vol. 2018, Article ID 2157937, 10 pages, 2018.

[22] A. T. de Almeida, C. A. V. Cavalcante, and M. H. Alencar, Multicriteria and Multiobjective Models for Risk, Reliability and Maintenance Decision Analysis, vol. 231, Springer, Berlin, Germany, 2015.

[23] M. Doumpos and C. Zopounidis, Multicriteria Analysis in Finance, Springer International Publishing, 1st edition, 2014.

[24] J.-Q. Wang, J.-J. Peng, H.-Y. Zhang, and X.-H. Chen, “Outranking approach for multi-criteria decision-making problems with hesitant interval-valued fuzzy sets," Soft Computing, pp. 1-12, 2017.

[25] L. Ferreira, D. Borenstein, M. B. Righi, and A. T. de Almeida Filho, "A fuzzy hybrid integrated framework for portfolio optimization in private banking," Expert Systems with Applications, vol. 92, pp. 350-362, 2018.

[26] R. Nie, Z. Tian, X. Wang, J. Wang, and T. Wang, "Risk evaluation by FMEA of supercritical water gasification system using multigranular linguistic distribution assessment," Knowledge-Based Systems, 2018.

[27] V. Mousseau and R. Slowinski, "Inferring an ELECTRE TRI Model from Assignment Examples," Journal of Global Optimization, vol. 12, no. 2, pp. 157-174, 1998.
[28] M. Doumpos and C. Zopounidis, Multicriteria Decision Aid Classification Methods, vol. 65, Kluwer Academic Publishers, 2002.

[29] R. P. Palha, A. T. De Almeida, and L. H. Alencar, "A model for sorting activities to be outsourced in civil construction based on ROR-UTADIS," Mathematical Problems in Engineering, vol. 2016, Article ID 9236414, 15 pages, 2016.

[30] P. Kefer, D. D. Milanovic, M. Misita, and A. Zunjic, "Fuzzy Multicriteria ABC Supplier Classification in Global Supply Chain," Mathematical Problems in Engineering, vol. 2016, Article ID 9139483, 11 pages, 2016.

[31] M. Barbati, S. Greco, M. Kadziński, and R. Słowiński, "Optimization of multiple satisfaction levels in portfolio decision analysis," Omega (United Kingdom), vol. 78, pp. 192-204, 2018.

[32] C. C. G. Famá and L. H. Alencar, "A Classification Model for Managers by Competencies?: A Case Study in the Construction Sector," Mathematical Problems in Engineering, vol. 2017, Article ID 1303916, 16 pages, 2017.

[33] C. J. J. D. Figueiredo and C. M. D. M. Mota, "A Classification Model to Evaluate the Security Level in a City Based on GIS-MCDA," Mathematical Problems in Engineering, vol. 2016, Article ID 3534824, 10 pages, 2016.

[34] H. Peng and J. Wang, "Outranking Decision-Making Method with Z-Number Cognitive Information," Cognitive Computation, pp. 1-17, 2018.

[35] P. Ji, H.-Y. Zhang, and J.-Q. Wang, "A projection-based outranking method with multi-hesitant fuzzy linguistic term sets for hotel location selection," Cognitive Computation, pp. 1-15, 2018.

[36] A. T. de Almeida, M. H. Alencar, T. V. Garcez, and R. J. Ferreira, "A systematic literature review of multicriteria and multiobjective models applied in risk management," IMA Journal of Management Mathematics, vol. 28, no. 2, pp. 153-184, 2017.

[37] L. Wang, J. Peng, and J. Wang, "A multi-criteria decisionmaking framework for risk ranking of energy performance contracting project under picture fuzzy environment," Journal of Cleaner Production, vol. 191, pp. 105-118, 2018.

[38] C. Zopounidis, E. Galariotis, M. Doumpos, S. Sarri, and K. Andriosopoulos, "Multiple criteria decision aiding for finance: an updated bibliographic survey," European Journal of Operational Research, vol. 247, no. 2, pp. 339-348, 2015.

[39] F. Pasiouras, C. Gaganis, and C. Zopounidis, "Multicriteria classification models for the identification of targets and acquirers in the Asian banking sector," European Journal of Operational Research, vol. 204, no. 2, pp. 328-335, 2010.

[40] M. Doumpos, K. Pentaraki, C. Zopounidis, and C. Agorastos, "Assessing country risk using a multi-group discrimination method: A comparative analysis," Managerial Finance, vol. 27, no. 8, pp. 16-34, 2001.

[41] S. Greco, B. Matarazzo, R. Slowinski, and S. Zanakis, "Global investing risk: a case study of knowledge assessment via rough sets," Annals of Operations Research, vol. 185, pp. 105-138, 2011.

[42] Y.-C. Hu and C.-J. Chen, "A PROMETHEE-based classification method using concordance and discordance relations and its application to bankruptcy prediction," Information Sciences, vol. 181, no. 22, pp. 4959-4968, 2011.

[43] M. Doumpos and J. R. Figueira, "A multicriteria outranking approach for modeling corporate credit ratings: An application of the Electre Tri-nC method," Omega (United Kingdom), pp. 115, 2018.

[44] L. Yu, S. Wang, and K. K. Lai, "An intelligent-agent-based fuzzy group decision making model for financial multicriteria 
decision support: the case of credit scoring," European Journal of Operational Research, vol. 195, no. 3, pp. 942-959, 2009.

[45] Z. Zhang, G. Gao, and Y. Shi, "Credit risk evaluation using multi-criteria optimization classifier with kernel, fuzzification and penalty factors," European Journal of Operational Research, vol. 237, no. 1, pp. 335-348, 2014.

[46] M. Corazza, S. Funari, and R. Gusso, "Creditworthiness evaluation of Italian SMEs at the beginning of the 2007-2008 crisis: An MCDA approach," The North American Journal of Economics and Finance, vol. 38, pp. 1-26, 2016.

[47] J.-P. Brans and P. Vincke, "A preference ranking organisation method: (The PROMETHEE method for multiple criteria decision-making)," Management Science, vol. 31, no. 6, pp. 647656, 1985.

[48] M. Behzadian, R. B. Kazemzadeh, A. Albadvi, and M. Aghdasi, "PROMETHEE: a comprehensive literature review on methodologies and applications," European Journal of Operational Research, vol. 200, no. 1, pp. 198-215, 2010. 


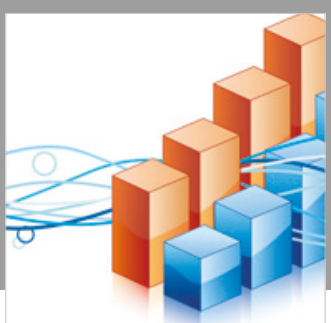

Advances in

Operations Research

\section{-n-m}
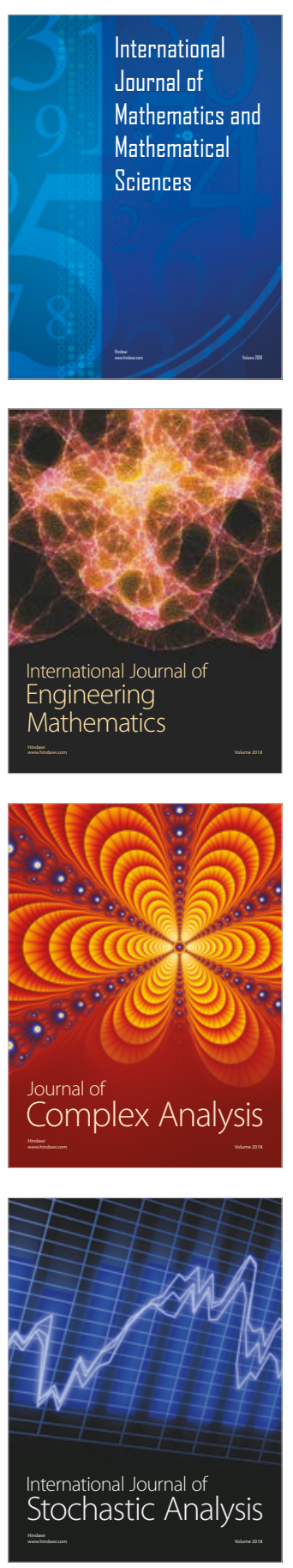
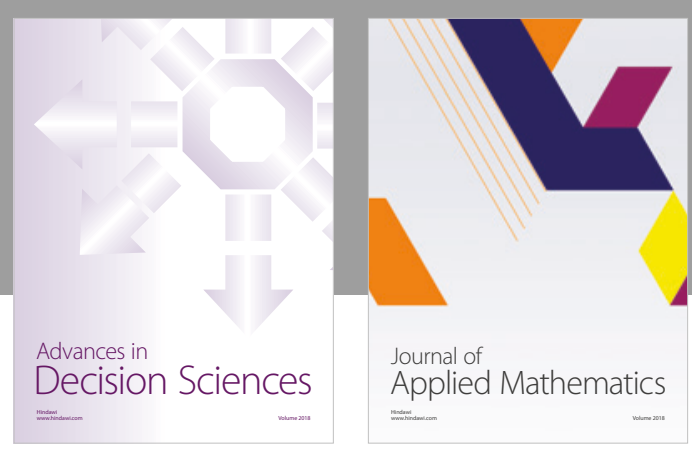

Journal of

Applied Mathematics
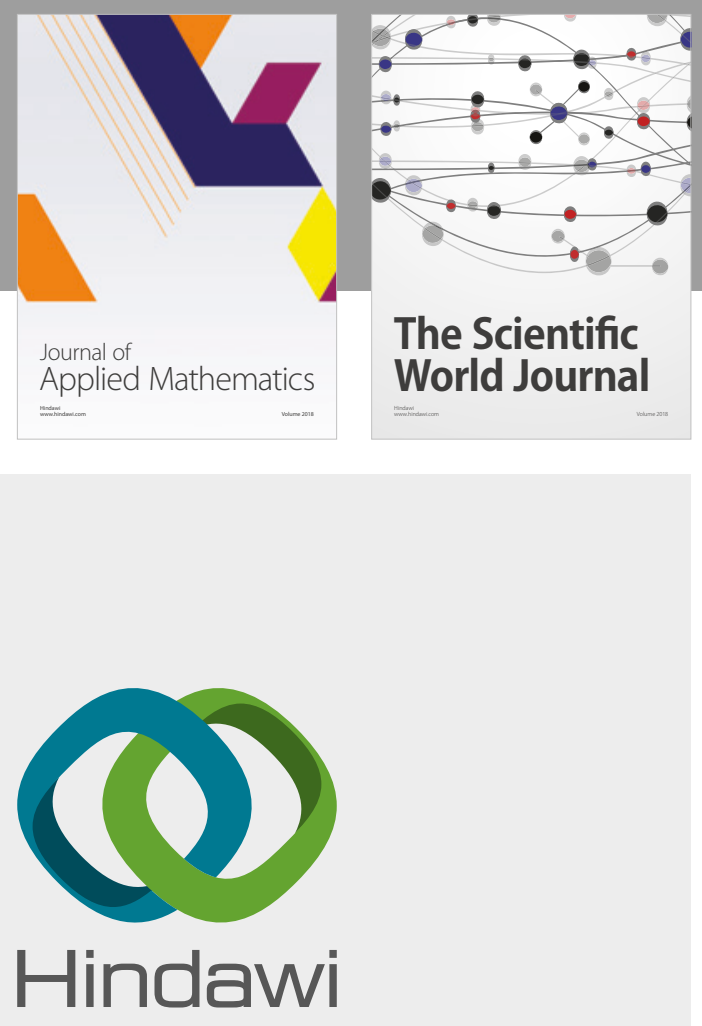

Submit your manuscripts at

www.hindawi.com

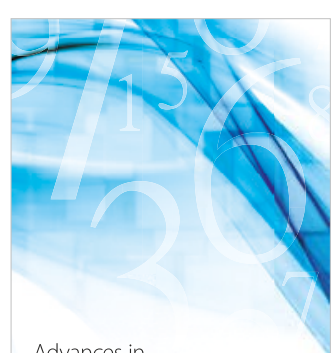

Advances in
Numerical Analysis
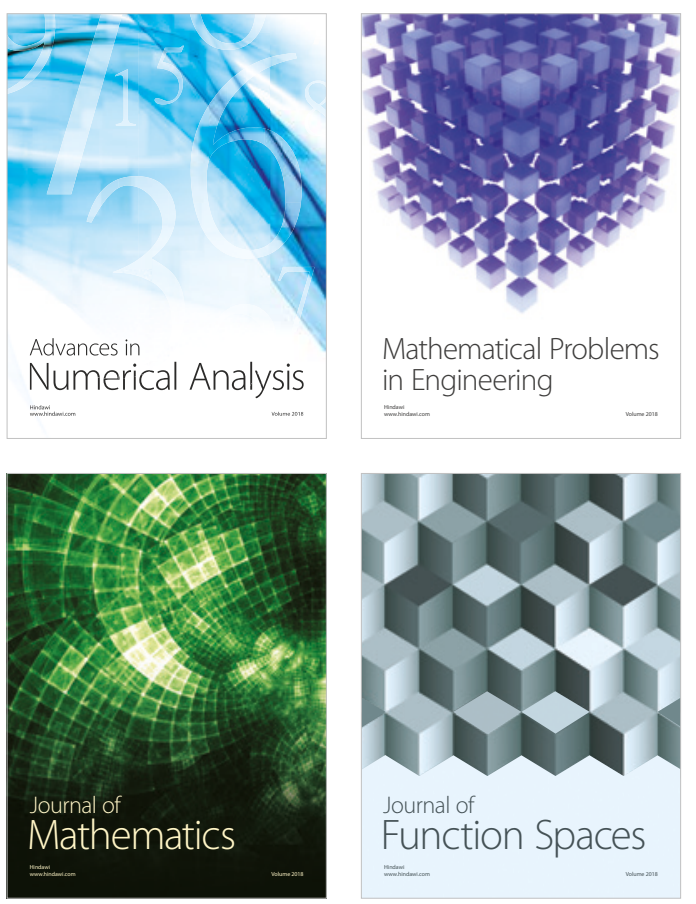

Mathematical Problems in Engineering

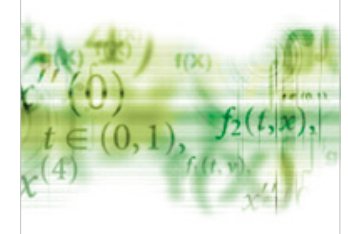

International Journal of

Differential Equations

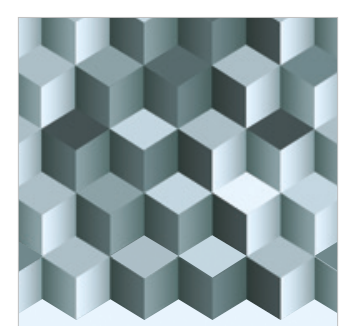

Journal of

Function Spaces
The Scientific

World Journal

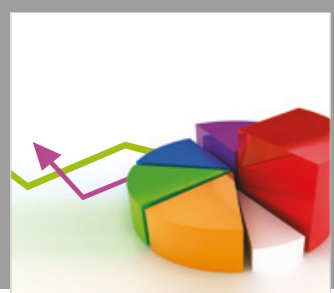

Journal of

Probability and Statistics
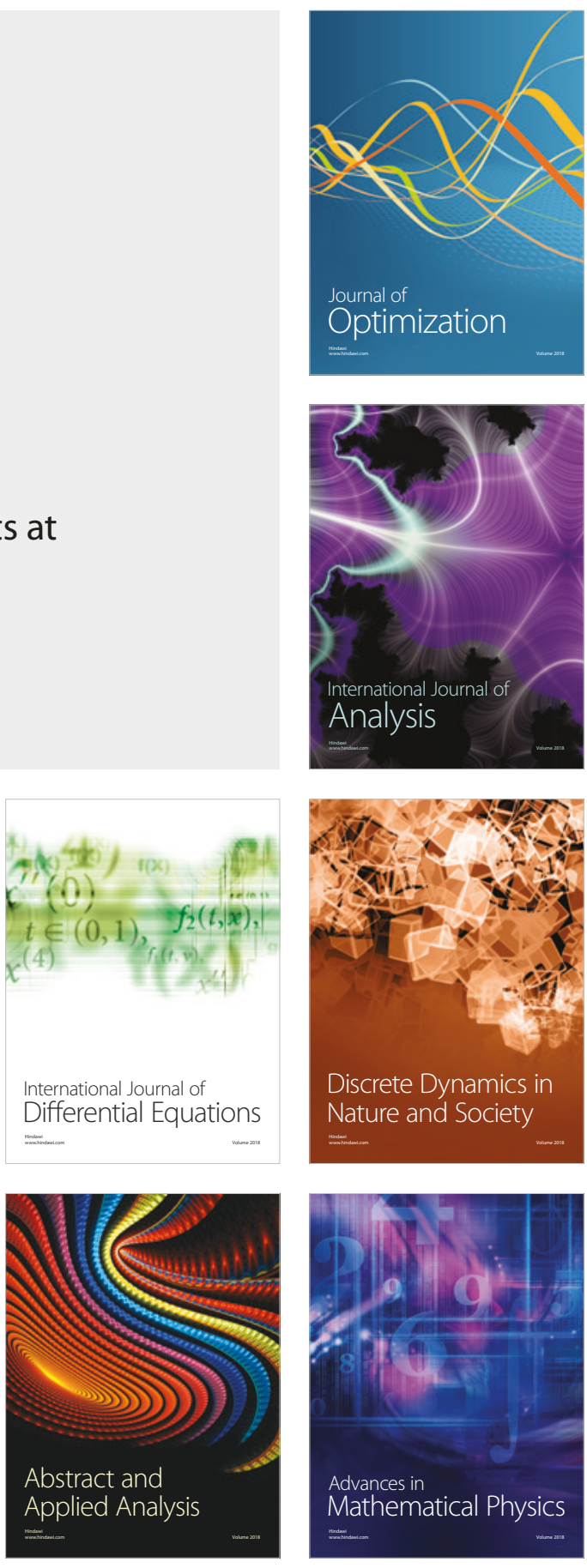